\title{
Taking aims seriously: repository research and limits on the duty to return individual research findings
}

\author{
Pilar Ossorio, PhD, JD ${ }^{1,2}$
}

Most discussions of researchers' duties to return incidental findings or research results to research participants or repository contributors fail to provide an adequate theoretical grounding for such duties. Returning findings is a positive duty, a duty to help somebody. Typically, such duties are specified narrowly such that helping is only a duty when it poses little or no risk or burden to the helper and does not interfere with her legitimate aims. Under current budgetary and personnel constraints, and with currently available information technology, routine return of individual findings from research using repository materials would constitute a substantial burden on the scientific enterprise and would seriously frustrate the aims of both

"You don't have to help anybody. That's what this country is all about." (Jerry Seinfeld) ${ }^{1}$

\section{INTRODUCTION}

Theoretical frameworks concerning the ethics of research on human participants have developed very little since the Nuremberg Code was set forth. ${ }^{2}$ The Belmont Report ${ }^{3}$ and the subsequent regulations for the protection of human subjects drew inspiration from the Code and followed it in many respects. To the extent that researchers' duties have been specified in more detail, most scholars have focused on negative duties, duties to refrain from imposing unjustifiable risk on research participants. Recently, however, the bioethics literature has taken on the question of researchers' positive duties, duties to bring about a particular state of affairs for another, or to provide the other with some benefit. Without a robust theoretical underpinning, however, the alleged duties may appear arbitrary.

This article examines some implications of grounding secondary researchers' duties to return incidental findings (IFs) and research results (RRs) in a general "duty to help," and in particular, how such a grounding illuminates the scope of duties to return. The particular focus here is on secondary researchers' duties to return genomic IFs or RRs to people who contributed biological material or data to research repositories (sometimes referred to as "biobanks"). The propositions discussed apply to returning research findings generally, but the question here is what conclusions one ought to draw when applying these propositions to secondary research. Properly grounding and specifying researchers' "duty of return" will scientists and specimen/data contributors. In most cases, researchers' limited duties to help repository contributors probably can be fulfilled by some action less demanding than returning individual findings. Furthermore, the duty-to-return issue should be analyzed as a conflict between (possibly) helping some contributors now and (possibly) helping a greater number of people who would benefit in the future from the knowledge produced by research.

Genet Med 2012:14(4):461-466

Key Words: biobank; duties; genomics; research ethics; supererogation

help explain its limits. This article considers questions of duty, not whether and when returning research findings might be permissible but not obligatory.

Throughout this article the terms "IF," "RR," "secondary research," and "secondary researcher" will be defined as they are in Wolf et al., the primary report of a recent working group on incidental findings in genomics research. In particular, secondary research is that conducted by researchers who obtain data and/or biospecimens from a repository and who were not themselves the original collectors of the data and/or biospecimens. Secondary research does not refer to the activities of repositories themselves, or to the activities of scientists who initially collect and analyze data and/or specimens. The term "secondary" does not indicate that the research under consideration is less important than other types of research, or that the researchers are less meritorious than others.

Individuals whose specimens or data are deposited in a repository or used in secondary research will be referred to as "contributors." The term "participant" is reserved for living persons about whom scientists obtain information through intervention or interaction, or about whom scientists obtain identifiable private information, regardless of whether a Common Rule exception applies. ${ }^{5}$

This analysis assumes that researchers and ethicists who argue for a duty to return IFs or RRs believe that, at least in some circumstances, returning would benefit the contributor. Furthermore, although contributors might want to receive IFs or RRs for reasons other than medical benefit (e.g., curiosity), this article assumes that the most morally compelling reason

${ }^{1}$ Morgridge Institute for Research, Madison, Wisconsin, USA; ${ }^{2}$ University of Wisconsin Law School, Madison, Wisconsin, USA. Correspondence: Pilar Ossorio (pnossorio@wisc.edu) Submitted 20 September 2011; accepted 6 January 2012; advance online publication 8 March 2012. doi:10.1038/gim.2012.5 
for imposing a duty to return is that contributors and participants also believe learning of research findings could (at least sometimes) benefit them.

\section{DISCUSSION}

\section{Grounding a "duty to return" in general duties to help}

Scholars have based a duty to return individual IFs or RRs on a number of different ethical principles and theories. These include norms underlying the Common Rule, reciprocity, respect for persons, and a duty of ancillary care.$^{6-8}$ In deference to spatial limitations, this article cannot undertake a critique of the arguments for each of these approaches, but it takes none of them as adequate. Miller, Joffe, and Mello ${ }^{9}$ rest a duty to return IFs on the "duty to help," which seems the best theoretical fit.

This article explores whether and to what degree a duty to help might ground a duty to return IFs or RRs. Unlike Miller and colleagues, or others who have argued in favor of a robust duty to return, this article does not consider returning findings as a distinctively professional or role-based duty. Whether there are professional or role-based duties beyond contractual ones is a matter of debate..$^{10}$ To argue, without being tautological, that the duty to return IFs or RRs is attached to the role of "scientist," one must specify what features of the role, the context in which it is enacted, or the institutions of which the role is a part, give rise to the duty. The bioethics literature still lacks adequate specifications of this sort, and none is attempted here.

In the context of duties to return, other commentators' appeals to professional or role-based duties seem reducible to the points that biomedical researchers possess specialized knowledge and that research activities provide scientists access to information (IFs or RRs) that may be unavailable to contributors/participants or their health-care providers. This article asks whether people who have the relevant specialized knowledge and access to IFs or RRs have a duty to return, regardless of whether those people are scientists. Because the analysis herein is not necessarily attached to the role of scientist, it could apply to repository personnel or other institutional actors who are not scientists or who did not carry out the research that generated the IFs or RRs in question.

Duties to help are a species of "positive duty" - moral requirements to produce a good or bring about a state of affairs on another person's behalf. Such duties typically involve making another person better off than he or she otherwise would have been had the aid not occurred. In these cases, the helper did not create or cause the danger; the helper is a bystander. ${ }^{11}$ The ethical question is whether the bystander may allow harm to occur, or whether he or she ought to prevent the bad outcome. Scholars cannot entirely agree on why people ought to help each other, or on the appropriate moral distinctions between situations in which helping is obligatory versus supererogatory. ${ }^{12-18}$ Nonetheless:

"It is commonly thought that we may sometimes have a duty to help people, at least when the sacrifice to ourselves is not great. It is also commonly thought that if the efforts required of us to help are high, helping is supererogatory, i.e., beyond the call of duty. The personal preference not to make the large effort, or to pay the large cost, may outweigh considerations in favor of helping ... . Likewise, if I must sacrifice an important personal goal to help someone, helping is commonly considered supererogatory." ${ }^{\prime 19}$

Scanlon describes a similar "Principle of Helpfulness": if a person can be of great help to somebody else (i.e., save her a great deal of time, money, irritation) in pursuing an important life project, at essentially no cost/burden to the helper, it would be wrong not to help absent a compelling reason not to help. ${ }^{20}$

The preceding are not full specifications of a duty to help. For instance, there is probably a knowledge requirement-the bystander must know that the other person is in danger, and perhaps the bystander must know that he or she can help or how he or she can help. However, knowing that another person is in danger is not, by itself, enough to ground a duty to help. Extending this insight to the research context, one could argue that researchers' knowledge or potential knowledge of significant IFs or RRs is not, by itself, enough to ground a duty to help contributors.

Researchers' duties to return IFs or RRs are affirmative duties. ${ }^{21}$ In the secondary research context in particular, scientists are "bystanders" with respect to contributors" underlying harmful or potentially harmful biological states that may be revealed as IFs or RRs. Genomic IFs and RRs consist of genotypes or DNA sequence information and the risks associated with that information., ${ }^{4,22}$ Researchers uncover or discover genotypes or alleles, and they compute risks associated with genetic variants, but researchers do not cause a contributor to possess any particular DNA sequence. The question is whether researchers are obliged to help contributors by disclosing such genomic information, and if so, under what circumstances and at what cost?

\section{Sacrificing to help others}

The degree to which one person must take on risks or burdens to help another is a matter of dispute. A few commentators have argued that people should aid or rescue even at great costs to themselves. ${ }^{17,23,24}$ One argument, focused entirely on acting so as to maximize overall good outcomes of some sort (a consequentialist or utilitarian argument), states that people should use their resources to help others up to the point where something else of comparable moral importance would be sacrificed..$^{24}$ For instance, a person should give her money to the most effective and efficient charities up to the point where giving one more dollar would create more disutility for the giver (or somebody else) than it would create utility in the world. Many commentators have criticized this position, and few believe that requirements to help are that stringent. Even if morality required that much of people, one could argue that if routinely returning individual research findings hindered the progress of socially 
beneficial science, and therefore fewer people experienced benefits from the application of new knowledge, then researchers ought not routinely return IFs or RRs.

The preceding section makes clear that many theorists limit the duty to help to one that requires only slight sacrifices or minimal risk to the helper, despite the great good a helper or rescuer could do. Commitment to individual liberty is often viewed as incompatible with forcing people to aid others, which is why ethicists may leave benefiting others to the realm of the supererogatory, and why US law is extremely averse to enforcing either criminal or civil duties to aid others. ${ }^{11,25,26}$ (Jerry Seinfeld ${ }^{1}$ was essentially right!) A commitment to liberty entails that people can pick the valuable things in the world on which to focus their time and energy.

Moral constraints forbid people to cooperate with unjust systems or to harm others without excuse or justification, but within those constraints people are free to form the goals and engage in the pursuits that make life meaningful for them. If too much aid were obligatory, people would constantly be sacrificing their own projects and aims to help others, and the duty to help would be inconsistent with achieving or promoting other valuable goods. Requiring people to set aside their meaningful life projects to confer benefit on others would be, in Scanlon's words, "intolerably intrusive." ${ }^{.20}$ An agent-centered prerogative gives people the option of according greater weight to their own projects, interests, and aims than to those of other people. ${ }^{19}$

In genomics research, a contributor or participant is rarely in an imminent, life-threatening situation that could be alleviated by returning an IF or RR, so a strong duty to rescue seems inapposite; but secondary researchers may still have a duty to help. In some cases, secondary researchers will have information that could be extremely valuable to an individual contributor in achieving important life goals. However, even if researchers know such information, whether a duty to return arises would depend on the degree to which returning would burden scientists or the scientific enterprise, and on whether scientists have other good reasons not to return individual findings.

Duties to help are generally limited to actions that do not require the helper to sacrifice important life projects or aims, including scientific ones. Stripped to the barest essentials, philosophers of science traditionally consider its overarching aims to be "explanation and application."27 Empirically adequate scientific theories should allow people to better understand the world around and within them, and to change it in ways that improve the human condition. Another formulation states that science aims to produce theories of general application that are coherent, empirically accurate, and predictive. ${ }^{28}$

Joffe and Miller ${ }^{29}$ view social value as integral to biomedical science when they describe the overarching aim as "the pursuit of generalizable knowledge in the service of improved health" (emphasis added). In this article, I also assume that social value is part of the scientific axiology. Science is valuable as an endeavor to which society devotes significant resources and dedicates major institutions because it produces socially beneficial knowledge (which does not mean that all scientific knowledge is, in fact, socially beneficial). Whether producing socially beneficial knowledge is a duty, or a very valuable supererogatory activity, is a matter of debate. ${ }^{29,30}$ Even if the pursuit of medical knowledge is not anybody's duty, the value of this aim still outweighs the value of many other goods.

Applying general principles regarding duties to help to the question of returning IFs or RRs suggests that there is no duty to return IFs or RRs if doing frustrates scientists' aim of producing generalizable knowledge. It matters that this aim is somebody's important aim, and if returning research findings unduly burdens this aim, then returning likely would be supererogatory. Scientists are at liberty to pursue this aim to the extent that they do not harm others in doing so. It has long been a concern of research ethicists that scientists not justify the imposition of inappropriate risk on research participants by pointing to the cumulative, long-term benefit the research might produce. However, when considering positive duties, such as helping contributors by returning IFs or RRs, one's noble aims can override other people's interests.

In the real world of limited resources for science, resources spent on returning IFs and RRs likely will come out of research budgets rather than from additional funds. ${ }^{31}$ If the resources for return come from research budgets, then money spent on returning will not be spent on generating socially beneficial knowledge. The issue is really a conflict between (potentially) helping some research contributors or (potentially) helping a greater number of future beneficiaries of medical science. Even for scholars whose ethical theories are based on considerations other than maximizing aggregate utility or benefit, the amount of good produced can matter, particularly when the problem concerns positive (as opposed to negative) duties. In the research context, this line of thinking suggests that it will be morally preferable for scientists to act so as to bring about the greater good of producing socially beneficial knowledge unless scientists have some strong reason to benefit research contributors more than future medical beneficiaries.

It ought to be self-evident that the interests of future beneficiaries of research matter in discussions of researchers' duties; however, too often discussions of returning IFs and RRs completely ignore these "third-party interests" and instead focus solely on the researcher-contributor/participant dyad. Given that return of IFs and RRs is not costless, perhaps the proper question to ask is not whether researchers should confer this benefit on contributors, but whether researchers should confer this benefit on contributors at the expense of future beneficiaries of scientific advances.

Future advances in information technology might decrease the costs and increase the feasibility of "high throughput return" of IFs or RRs. ${ }^{32}$ Such advances would undermine the argument that stewardship of research resources militates against a routine duty to return. Furthermore, if people were to cease contributing to research repositories because there was no return of IFs or RRs, researchers would have pragmatic 
reasons to return individual information. Under the current state of affairs, however, return demands significant resources and there are no data indicating that a shortage of repository materials is attributable to prospective participants' refusals to contribute, even though IFs and RRs generally are not returned.

\section{Further limitations on the duty to help}

Philosophers have attempted to further distinguish situations in which people have duties to help from situations in which helping is supererogatory. In particular, philosophers have tried to explain many people's moral intuitions that one might have a duty to engage in an easy, life-saving rescue but not to give away one's money to aid starving children in famine-stricken countries (although doing so would probably promote good and might be morally better than other things one might do). Consider two cases, ACCIDENT and FAMINE: ${ }^{33}$

ACCIDENT: You come across a traffic accident in country $\mathrm{X}$, where you are visiting. You know that the victim will survive if and only if you stop to help. You can help by putting $\$ 100$ in a machine that will safely extract the victim from her crumpled car.

FAMINE: You receive a letter from a physician who works for a well-regarded, international famine relief agency. The letter asks you to send $\$ 100$ to save a famine victim in country $\mathrm{X}$. You know that a life will be saved if and only if you contribute.

The contrived means of saving the victim in ACCIDENT is used to better equalize these cases by creating a situation in which spending $\$ 100$ is the means to saving a life in both cases. ${ }^{34}$ The question is whether these cases are morally distinguishable, and if so, why? Many people have the intuition that they are distinguishable, that there is a duty to aid in ACCIDENT but not in FAMINE.

One suggestion as to why the cases are distinguishable is that FAMINE presents an aggregation problem ${ }^{33}$ while ACCIDENT does not. ACCIDENT is a relatively discrete event, the rescuer responds once and it is over. And such events happen rarely in any potential rescuer's life. FAMINE is not a discrete event. The $\$ 100$ might save the victim now, but what about next month, will she need another $\$ 100$ ? And what about her siblings, parents, and cousins? One never knows when FAMINE will be over. The cumulative cost of aiding in certain types of situations can be extremely high, even if aiding in a single instance is not terribly costly. Scanlon responds to this concern by limiting his Helping Principle such that the threshold of sacrifice takes account of previous instances of aid in response to a particular problem; the overall sacrifice should be modest. Under Scanlon's Principle one could not subdivide a burdensome request for help into many small requests. ${ }^{20}$

A duty to return IFs and RRs may also face the aggregation problem if the duty is not specified in an appropriately narrow manner. Consider twenty-first century genomics research using repository materials, in which thousands of contributors' specimens and data might be used for one study, and each contributor could be genotyped at millions of markers, or could have his or her entire exome or genome sequenced. There will be findings of medical or reproductive importance for every contributor in the study, and these findings will differ from one contributor to another ${ }^{22,35}$ Then, suppose the scientists go back to the same contributors' genotypes or sequences a few years later, and in light of newly acquired knowledge the scientists find additional meaningful information that could be returned. And, the scientists conduct a second experiment with materials from thousands more contributors. The burdens and costs of returning individual IFs and RRs-including money, people's time, and the opportunity cost of not doing more research because one is engaged in returning information to contributors-aggregate swiftly.

At first glance, the role proposed by Wolf et al. ${ }^{4}$ for repositories to act as clearinghouses regarding IFs and RRs, and to conduct some of the activities involved in return, would decrease the burdens on secondary researchers. However, if repositories take on too large a burden in returning individual information, then accessing the repository could cost scientists substantially more, or repositories could become slower at accumulating and distributing specimens or data. The entire scientific enterprise might be burdened, including the secondary research projects first thought to be protected by placing the duty of return on repositories. If repositories are necessary institutions for achieving scientists' individual scientific aims and for achieving the social benefits promised by science, then we ought to consider excessive burden on these institutions as a reason there might not be a duty to return IFs and RRs. Placing the burdens of returning IFs and RRs on repositories runs the risk of changing these institutions so substantially that they can no longer serve the aim of promoting science.

Another suggestion for distinguishing ACCIDENT from FAMINE is that the helper has much more reliable information about ACCIDENT than FAMINE. The helper can predict the consequences of his or her actions better in ACCIDENT (although people's knowledge about and ability to predict outcomes in ACCIDENT are far from perfect). ${ }^{33}$ Practical morality takes account of the opacity of real-world situations and makes persons more responsible for situations they know best. ${ }^{33}$ In the research context, this consideration might apply somewhat differently to secondary researchers than to those who directly interact with participants. Recall that this article focuses particularly on secondary researchers' obligations to return IFs or RRs in a situation in which secondary researchers obtain data and/or biospecimens from repositories and have no interaction with contributors.

The scientist who directly interacts with a participant can better ascertain whether returning findings would produce 
benefit. Such a scientist can determine whether the participant already knows about a biological anomaly observed during research, whether the participant has medical insurance and is in position to follow up information about an RR or IF, whether the participant would welcome the information, and a host of other relevant factors. A secondary researcher, who may be from a different country and culture than the contributor, and who may be using the biological materials or data long after they were contributed, has far less and less reliable information on which to judge whether return will, in fact, constitute a benefit. ${ }^{22,35,36}$ If secondary researchers have less information, and less reliable information, with which to predict benefit from returning IFs or RRs, then they probably have more limited duties of return than researchers who interact with research participants.

As Beskow and Burke ${ }^{36}$ eloquently observe, "depth of relationship is ... a critical contextual factor in analyzing researchers' obligations ..." to return individual genetic findings. If one can say that secondary researchers have relationships with contributors, such relationships would be characterized as extremely shallow, and therefore, as not underwriting strong duties. (Note that this analysis does not rule out the possibility that other contextual factors could ground secondary researchers' duties to return.)

At this juncture, it is worth noting some important differences between the hypothetical cases and secondary research. ACCIDENT, FAMINE, and other similar cases in the duty-torescue-or-help scholarship assume that the agent and the victim are complete strangers. Repository contributors and secondary researchers are strangers, but they are tied together by scientific practices in morally meaningful ways. For instance, secondary researchers impose informational risks on contributors. Many scientists believe that the risk of information from a research database being linked back to a particular contributor and causing social or economic harm is currently small. ${ }^{37}$ Nonetheless, most scientists acknowledge some informational risks, and some contributors will be exposed without their knowledge or consent. Contributors' vulnerability to informational risks created by secondary scientists seems clearly related to scientists' duties not to harm. Scientists discharge the relevant negative duties by taking proper information security precautions. It is not apparent, however, how or why repository contributors' vulnerability to informational risks would give rise to positive duties for scientists.

Another reason why helpers' duties to strangers may differ from secondary researchers' duties to contributors is that contributors confer benefit on individual scientists and on the scientific community by providing specimens and data. Secondary researchers' individual and collective interests and aims are advanced because they have the use of specimens and data. Even though secondary researchers and contributors will not have interacted, and contributors may not even know of their contribution to research, the conferral of benefit means that scientists and contributors are not in the same relationship to each other as most strangers.
The quantum of benefit any contributor confers on scientists or the scientific enterprise is generally miniscule. The collective contribution from many people is what usually creates value in science, although the book "The Immortal Life of Henrietta Lacks" ${ }^{\prime \prime}$ serves as a reminder that there will be rare cases in which one individual confers an enormous benefit on scientists and society. Regardless of the quantum of benefit to science, from the contributor's perspective, the experience of giving a specimen or data, and the importance of what was given, may not be small.

That individual contributors confer some (usually) tiny benefit on scientists may give secondary researchers a reason to provide reciprocal benefit, or to benefit contributors before benefiting others. Having a reason to confer reciprocal benefit does not necessarily transform a supererogatory act of returning IFs or RRs into a duty, however. Furthermore, if secondary scientists have duties to help contributors before helping other strangers, such duties still could be relatively weak or undemanding.

An equally plausible argument regarding what scientists owe contributors in light of the benefit contributors confer is that scientists ought to honor the contribution by, for instance, acting as good stewards of the specimens and data. Good stewardship might involve not wasting specimens, maintaining data in useful formats, and otherwise acting to ensure that the full value of the contribution is realized (consistent with other ethical constraints, such as use restrictions arising from the consent process).

For the most part, people who properly consent to contribute their biological materials and data to a research repository probably do not intend to confer benefit on any particular researcher. By definition, secondary researchers and contributors have no interaction, so it is highly unlikely that a contributor would intend to benefit particular secondary researchers. Whether contributors' scientific or social aims are identical to those of scientists, it must be the case that a person who knowingly and intentionally provides specimens and/or data to a repository does so out of an intention to advance scientific progress generally, or to advance a particular body of knowledge, such as "knowledge about Alzheimer disease." If the aim of advancing science is also one of contributors' important aims, then policy makers should be reluctant to frustrate it by imposing too stringent a duty to return IFs and RRs.

Just like other members of society, contributors also may benefit in the future from new medical knowledge that emerges out of the research to which they contributed, or from other research done by the same researchers or the same research institutions. Contributors' other-regarding interests in family members and friends may also be advanced if these cherished others benefit from new medical knowledge. Thus, the research enterprise includes a version of reciprocity between researchers and contributors even if contributors do not receive IFs or RRs. Whether contributors will benefit from the science is, of course, more speculative than whether scientists will benefit from contributions of specimens and data. 
In conclusion, secondary researchers' duties to help contributors may be slightly more demanding than a duty to help other strangers; nonetheless, researchers' duties to contributors are constrained by the degree to which helping would burden the scientific aim of producing socially beneficial knowledge. In most cases, secondary researchers' duty to help probably will be satisfied by something less than returning individual IFs or RRs. Returning aggregate results to contributors might satisfy secondary researchers' duties, although an argument for this proposition is not developed here. For secondary researchers, returning individual IFs or RRs may be obligatory only in rare situations when the individual finding would be of utmost importance to the contributor and returning would not be unduly burdensome to the secondary researchers.

Returning IFs or RRs may produce a great deal of good in some circumstances. The point of this article is that people often have no duty to produce the good. If returning IFs and RRs is usually supererogatory for secondary researchers, one could still argue that returning is sometimes morally superior to not doing so. The questions of when it is permissible to return IFs or RRs, or under what circumstances it would be better to do so, are not addressed here.

\section{ACKNOWLEDGMENTS}

Work for this article was supported by the University of Wisconsin, the Morgridge Institute for Research, and National Institutes of Health grant no. 2-R01-HG003178 (S. Wolf, principal investigator), Managing Incidental Findings and Research Results in Genomic Biobanks and Archives. The author thanks Susan Wolf, two anonymous reviewers, and Melissa Hatch for very helpful comments on an earlier draft of this article.

\section{DISCLOSURE}

The author declares no conflict of interest.

\section{REFERENCES}

1. Seinfeld: The Finale. [NBC television broadcast] 1998; transcript on file with the author. http://www.seinfeldscripts.com/TheFinale.htm.

2. Nuernberg Military Tribunals. Trials of War Criminals Before the Nuremberg Military Tribunals Under Control Council Law No. 10: The Medical Case. Vols. I \& II. U.S. Government Printing Office: Washington, DC, 1946-1949.

3. National Commission for the Protection of Human Subjects of Biomedical and Behavioral Research. The Belmont Report: Ethical Prinicples and Guidelines for the Protection of Human Subjects of Research. Federal Register 1979;44:23192-23197.

4. Wolf SM, Crock BN, Van Ness B, et al. Managing incidental findings and research results in genomic research involving biobanks and archived datasets. Genet Med 2012;14:361-384.

5. U.S. Department of Health and Human Services. Federal Policy for the Protection of Human Subjects. Federal Register 1991;56:28003-28028, as amended by Fed. Regist. 22005;28070(28120):36325-36328. Codified at 28045 CFR Part 28046

6. Richardson HS. Incidental Findings and Ancillary-Care Obligations. J Law Med Ethics 2008;36:256-270.
7. Shalowitz DI, Miller FG. Disclosing individual results in research: implications of respect for participants. JAMA 2005;294(6):737-740.

8. Wolf SM, Paradise J, Nelson CA, Kahn JP, Lawrenz F. Managing incidental findings in human subjects research: analysis and recommendations. J Law Med Ethics 2008;36:219-248.

9. Miller FG, Mello MM, Joffe S. Incidental findings in human subjects research: what do investigators owe research participants. J Law Med Ethics 2008;36(2):271-279

10. Hardimon MO. Role obligations. The Journal of Philosophy 1994;91(7): 333-363.

11. McIntyre A. Guilty bystanders? On the legitimacy of duty to rescue statutes. Philosophy and Public Affairs 1994;23(2):157-191.

12. Foot $P$. The problem of abortion and the doctrine of the double effect. Oxford Review 1975;5:5-15.

13. Hanser M. Why are killing and letting die wrong? Philosophy and Public Affairs 1995;24(3):175-201.

14. Kamm FM. Killing and letting die: methodological and substantive issues. Pacific Philosophical Quarterly 1983;64:300-303.

15. Trammell RL. Saving life and taking life. Journal of Philosophy 1975;72(5):131-137.

16. Tooley M. Abortion and infanticide. Philosophy and Public Affairs 1972;2(1):37-65.

17. Unger PK. Living High and Letting Die: Our Illusion of Innocence. Oxford University Press: New York, 1996.

18. Walen A. Doing, allowing, and disabling: some principles governing deontological restrictions. Philosophical Studies 1995;80(2):183-215.

19. Kamm FM. Supererogation and obligation. The Journal of Philosophy 1985;82(3):118-138.

20. Scanlon TM. What We Owe Each Other. The Belknap Press of Harvard University Press: Cambridge, 1998.

21. Beskow LM. Considering the nature of individual research results. Am J Bioeth 2006;6(6):38-40.

22. Cho MK. Understanding incidental findings in the context of genetics and genomics. J Law Med Ethics 2008;36:280-285.

23. Rachels J. Killing and starving to death. Philosophy 1979;54(208):159-171.

24. Singer P. Famine, affluence and society. Philosophy and Public Affairs 1972;1:229-243.

25. Franklin MA, Ploeger M. Of rescue and report: should tort law impose a duty to help endangered persons or abused children? Santa Clara Law Review 2000;40:991-1026.

26. Romohr PW. A right/duty perspective on the legal and philosophical foundations of the no-duty-to-rescue rule. Duke Law Journal 2006;55:1025-1057.

27. Koertge N. Science, values, and the value of science. Philosophy of Science 1998;67(suppl 1):S45-S57.

28. Laudan L. Science and Values: The Aims of Science and Their Role in Scientific Debate. University of California Press: Berkeley, 1984.

29. Joffe S, Miller FG. Bench to bedside: mapping the moral terrain of clinical research. The Hastings Center Report 2008;38(2):30-42.

30. Jonas $\mathrm{H}$. Philosophical reflections on experimenting with human subjects. Daedalus 1969;98(2):219-247.

31. Ossorio PN. Letting the gene out of the bottle: a comment on returning individual research results to participants. Am J Bioeth 2006;6(6):24-25.

32. Kohane IS, Mandl KD, Taylor PL, Holm IA, Nigrin DJ, Kunkel LM. Reestablishing the researcher-patient compact. Science 2007;316: 836-837.

33. Schmidtz D. Islands in a sea of obligation: limits of the duty to rescue. Law and Philosophy 2000;19(6):683-705

34. Kamm FM. Does distance matter morally to the duty to rescue? Law and Philosophy 2000;19(6):655-681.

35. Clayton EW. Incidental findings in genetics research using archived DNA. J Law Med Ethics 2008;36:286-291.

36. Beskow LM, Burke W. Offering individual genetic research results: context matters. Sci Trans/ Med 2010;2(38):1-5

37. Ossorio PN. Bodies of data: genomic data and bioscience data sharing Social Research, in press.

38. Skloot R. The Immortal Life of Henrietta Lacks. Crown: New York, 2010. 